\title{
The use of perioperative chemotherapy in patients undergoing radical cystectomy for bladder cancer in Quebec (Canada), 2000-2016
}

Michel D. Wissing, MD/PhD ${ }^{1,2}$; Wassim Kassouf, MD, CM, FRCSC ${ }^{1}$; Simon Tanguay, MD, FRCSC $^{1}$; Armen G. Aprikian, MD, FRCSC ${ }^{1,2}$

${ }^{1}$ Department of Surgery, McGill University Health Centre, Montreal, QC, Canada; ${ }^{2}$ Department of Oncology, McGill University, Montreal, QC, Canada

Acknowledgments: The authors wish to thank the RAMQ, MSSS, ISQ, and CAI for allowing analyses of the Quebec provincial registry data. They would also like to thank Dr. Fabiano Santos for providing the SAS programming codes he used for analyses of an older version of the bladder cancer cohort, and Ana O'Flaherty for her assistance with the data cleaning.

Financial support: Dr. Wissing was funded by a Fellowship Award from the Canadian Institutes of Health Research (CIHR), McGill University, the Richard Tomlinson Chair in Urology at McGill University held by Dr. Aprikian, and the McGill University Health Centre. The funding institutions did not have any influence on the design and conduct of the study; collection, management, analysis, and interpretation of the data; and preparation, review, or approval of the manuscript.

Cite as: Can Urol Assoc J 2019 November 29; Epub ahead of print. http://dx.doi.org/10.5489/cuaj.6094

Published online November 29, 2019

$* * *$

\section{Abstract}

Introduction: Despite its proven benefit, studies have reported poor use of perioperative chemotherapy (POC) in bladder cancer (BC) patients undergoing radical cystectomy (RC). We evaluated POC use in Quebec between January 2000 and September 2016.

Methods: Using provincial health administrative databases, data were retrospectively collected from patients from two years before RC until December 2016 or death. Logistic regression was used to identify variables predicting POC use. Survival analyses were conducted using Cox regression. Analyzed covariates were age, sex, comorbidities, year of RC, residence and hospital region, distance to hospital, hospital type and size, and hospital's and surgeon's RC volume. Results: A total of 790/4656 patients (17.0\%) received POC. Neoadjuvant chemotherapy (NAC) use increased in recent years: 3.5\% (2009), 11.2\% (2012), and 20.7\% (2015). POC use was increased in patients with recent surgery, a younger age, less comorbidities, residing closer to the hospital of surgery, and a high surgeon's RC volume $(\mathrm{p}<0.05)$. For patients treated between 2013 
and 2016, a younger age (odds ratio [OR] 0.71; 95\% confidence interval [CI] 0.64-0.80 per five years), shorter distance to the hospital (OR 0.88 ; 95\% CI $0.77-0.99$ per $50 \mathrm{~km}$ ), surgery in an academic hospital (OR 1.86; 95\% CI 1.06-3.29), and recent surgery (OR 1.34; 95\% CI 1.14-1.58 per year) independently predicted NAC use. These NAC users had a significantly higher OS rate than patients without POC (hazard ratio 0.73; 95\% CI 0.55-0.97). Limitations include missing data on pathological staging.

Conclusions: NAC/POC use increased in Quebec but was lower compared to most developed countries. Its use was lower in patients residing further from the hospital and in those treated in non-academic hospitals.

\section{Introduction}

Radical cystectomy is the standard treatment for patients with localized muscle-invasive bladder cancer. ${ }^{1}$ In the early $2000 \mathrm{~s}$, randomized clinical trials concluded that patients with cT2-T4A urothelial carcinoma had better clinical outcomes when treated with neoadjuvant cisplatin-based combination chemotherapy. ${ }^{2-4}$ These findings resulted in the recommendation of neoadjuvant chemotherapy (NAC) for this patient population in several guidelines, including those by the Canadian Urology Association of 2019. ${ }^{1,5}$ More recent studies have further underscored the benefit of NAC use. ${ }^{6,7}$ If patients have not received NAC, they are recommended to receive adjuvant cisplatin-based combination chemotherapy (AC) when having pT3-T4 disease and/or positive lymph nodes at surgery, as randomized controlled trials showed improved progressionfree survival (PFS) and overall survival (OS) in these patients. ${ }^{1,8}$

However, the uptake of perioperative chemotherapy (POC) in clinical practice has been slow, and varies across the world. In Nordic European countries, NAC is considered for all eligible patients. ${ }^{9}$ In $2016,47 \%$ of all Swedish patients with muscle-invasive bladder cancer received cisplatin-based combination chemotherapy prior to cystectomy. ${ }^{10}$ In Japan, $83 \%$ of patients with cT2 or more advanced muscle-invasive bladder cancer received NAC in 20052016. ${ }^{11}$ Other countries have been less successful in the implementation of NAC. For example, in the National Cancer Database in the United States, NAC was administered to $32.2 \%$ of patients undergoing radical cystectomy for muscle-invasive bladder cancer in $2014,{ }^{12}$ and in South Korea, this percentage was only $8.4 \%$ in $2010-2013 .{ }^{13}$ For Canada, the most recent data is available from the Ontario Cancer Registry, in which POC and NOC use were $35 \%$ and $19 \%$ in 2009-2013, compared to $23 \%$ and $4 \%$ in 1994-2008, respectively. ${ }^{14}$ While this is a significant improvement, POC use differed across regions in Ontario, and was lower in older patients, patients with a lower socioeconomic status, and those treated by low-volume surgeons. 
We studied POC use in a large cohort of bladder cancer patients undergoing radical cystectomy in the Canadian province of Quebec between 2000 and 2016. We evaluated changes in chemotherapy use over the years, determinants for POC use and the clinical outcome of patients based on NAC and AC use.

\section{Methods}

\section{Study design, data acquisition, and study population}

This is a retrospective study of patients undergoing radical cystectomy for bladder cancer in Quebec. The study has been approved by the research ethics board of the McGill University Health Center (project number 2014-1059; latest renewal August $31^{\text {st }}, 2018$ ). The cohort was collected using data from the Quebec provincial health administrative agencies Régie de l'assurance maladie du Québec (RAMQ), Ministère de la Santé et des Services Sociaux (MSSS), and Institut de la statistique du Québec (ISQ). In total, 5148 patients were identified who underwent radical cystectomy between January 2000 and September 2016. This included all radical cystectomies conducted in the province in this timeframe, since these surgeries are only conducted in public hospitals in Quebec. During a rigorous selection process, we excluded 492 patients who had radical cystectomy for other indications than bladder cancer or who had their cystectomy performed by other surgeons than urologists, as previously described. ${ }^{15}$

All patient data were collected from two years before the radical cystectomy until death or the last day the patient was known to be alive before January $1^{\text {st }}, 2017$. The collected data consisted of all medical procedures performed in public hospitals, all hospital and emergency room admissions, intensive care unit stays, all prescribed medication bought in outpatient pharmacies by individuals covered by the Public Prescription Drug Insurance Plan (universal health coverage), and all deaths (including date and cause of death) in Quebec.

\section{Data analyses}

NAC use was defined as patients who had a medical act code for chemotherapy administration within the three months preceding the index date. Patients were considered to have received AC when they had a code for chemotherapy within 90 days after postoperative hospital discharge and did not have NAC.

Charlson's comorbidity index is a number between 0 and 33 based on a patient's age and comorbidities, ${ }^{16,17}$ and was estimated by evaluation of filed diagnostic codes and medication specifically used for certain diseases. We included codes filed both prior to and after radical cystectomy in our calculation of comorbidity indices. All patients had a minimum index of 2 , since all patients had a solid tumor. Region of residence and hospital were categorized into three groups: urban regions included cities with $>400,000$ inhabitants, rural regions did not have a city with $>100,000$ inhabitants, and an intermediate group included all regions with cities of 100,000400,000 inhabitants. Distance between a patient's residence and the hospital of radical 
cystectomy was calculated as the driving distance between the center of a patient's postal code and the hospital, as described previously. ${ }^{15}$ University-affiliated hospitals included all hospitals that train urology residents. Hospital size was determined based on the number of beds $(<250$, $250-499$, or $\geq 500$ beds). A hospital's or surgeon's radical cystectomy volume was calculated by dividing the total number of radical cystectomies by the years between the first and last radical cystectomy for bladder cancer of that hospital/surgeon in our database.

Overall survival was calculated as the time between radical cystectomy and death (or last follow-up). We described the definition of bladder cancer-specific deaths previously. ${ }^{15}$ Patients who died from other causes than bladder cancer were censored at the time of death in bladder cancer-specific survival calculations. Recurrence-free survival was defined as the time between radical cystectomy and first administration of chemo- or radiotherapy after surgery, or death due to bladder cancer. All chemo- and radiotherapy administered within three months after postoperative hospital discharge was considered adjuvant and/or salvage therapy, and therefore, this was not considered a recurrence. Instead, these patients were considered to have recurred when there was an interval of $\geq 3$ months between the adjuvant/salvage therapy and new chemoor radiotherapy, or when the patients died from bladder cancer.

\section{Statistical analyses}

All statistical analyses were conducted using Stata (v15.1, Statacorp, College Station, Texas, USA). Baseline characteristics were displayed as the median with interquartile range for continuous variables. Odds ratios and their respective $95 \%$ confidence intervals $(95 \% \mathrm{CI})$ were calculated using univariable and multivariable logistic regression models. In the multivariable models, we mutually adjusted for all variables included in the univariable analysis. In these analyses, year of surgery, age, Charlson's comorbidity index, distance between the patient's residence and hospital of surgery, and hospital's and surgeons' radical cystectomy volume were analyzed as continuous variables. Sex, region of residence, region of the hospital of surgery, and hospital type and size were analyzed as categorical variables. Patients with missing data were excluded from multivariable analyses. Survival analyses were conducted using the Kaplan-Meier method. ${ }^{18}$ Follow-up time was calculated using the reverse Kaplan-Meier method. ${ }^{19}$ Hazard ratios were calculated using Cox regression. ${ }^{20}$ In multivariable Cox proportional hazards models, we adjusted for the same variables as in logistic regression models.

\section{Results}

We identified 4656 patients with bladder cancer who had a radical cystectomy performed in Quebec between January 2000 and September 2016. Of these, 324 (7.0\%) and 466 (10.0\%) received NAC or AC, respectively. Over the years, the use of NAC has been increasing, with rates surpassing 10\% in 2012, and 20\% in 2015 (Figure 1). Between 2000 and $2011,9 \%$ to 17\% of patients received AC per year; however, AC use dropped below $8 \%$ after 2011. Baseline and 
surgery characteristics of patients are displayed in Table 1. Median age of patients receiving POC was 64 years (interquartile range 58-70 years), versus 70 years (interquartile range 63-76 years) in the rest of the cohort (odds ratio 0.76 per 5-year increment, 95\% CI 0.73-0.79; Table 2). Approximately three-quarters of the patients were male. Patients receiving POC had a significantly lower Charlson's comorbidity index (median 5 versus 7 , odds ratio $0.78,95 \% \mathrm{CI}$ 0.75-0.81). Slightly over half of the patients were treated in university-affiliated hospitals. The median time between the last cystoscopy/TUR-B (transurethral resection of the bladder) and radical cystectomy was 49 days (interquartile range 28-76 days), 42 days (interquartile range 2762 days) and 126 days (interquartile range 56-167 days) for patients who did not receive POC and those who received $\mathrm{AC}$ or NAC, respectively.

In a multivariable analysis (Table 2), year of surgery, age, Charlson's comorbidity index, distance between the residence and hospital, hospital size, and hospital's and surgeon's radical cystectomy volume were independent predictors for POC use, with adjusted odds ratios of 1.06 (95\%CI 1.05-1.08, per 1-year increment), 0.81 (95\%CI 0.77-0.86, per 5-year increment), 0.88 (95\%CI 0.84-0.92, per point increment), 0.91 (95\%CI 0.86-0.97, per 50km increase), 1.45 (95\%CI 1.20-1.76, comparing hospitals with 250-499 beds to those with $\geq 500$ beds), 0.91 (95\%CI 0.87-0.96, per 5/active year increment), 1.33 (95\%CI 1.16-1.52, per 5/active year increment), respectively. When analyzing patients who received NAC and AC as separate groups, independent predictors for NAC (Supplementary Table 1) were year of surgery (adjusted odds ratio 1.30, 95\% CI 1.26-1.35), age (adjusted odds ratio 0.76, 95\% CI 0.71-0.82), surgery in a university-affiliated hospital (adjusted odds ratio 1.69, 95\% CI 1.12-2.55), and hospital's radical cystectomy volume (adjusted odds ratio $0.89,95 \% \mathrm{CI} 0.82-0.96$ ). Year of surgery (adjusted odds ratio $0.95,95 \% \mathrm{CI} 0.93-0.97$ ), age (adjusted odds ratio $0.87,95 \% \mathrm{CI} 0.82$ 0.92), Charlson's comorbidity index (adjusted odds ratio $0.86,95 \% \mathrm{CI} 0.81-0.91$ ), distance to the hospital (adjusted odds ratio 0.90, 95\% CI 0.83-0.97), surgery in a university-affiliated hospital (adjusted odds ratio $0.70,95 \% \mathrm{CI} 0.50-1.00$ ), hospital size (adjusted odds ratio $1.71,95 \% \mathrm{CI} 1.34$ 2.17), and surgeon's radical cystectomy volume (adjusted odds ratio 1.34, 95\%CI 1.14-1.59) independently predicted AC use (Supplementary Table 2).

With a median follow-up time of 7.4 years (95\%CI 7.0-7.7 years), median overall, bladder cancer-specific, and recurrence-free survival were 3.3 years (95\%CI 3.0-3.6 years), 6.5 years (95\%CI 5.8-7.4 years), and 4.6 years (95\%CI 4.0-5.1 years), respectively. Patients who received $\mathrm{AC}$ had significantly worse overall survival (adjusted hazard ratio 1.32, 95\%CI 1.171.48), bladder cancer-specific survival (adjusted hazard ratio 1.66, 95\%CI 1.45-1.89), and recurrence-free survival (adjusted hazard ratio 1.71, 95\% $\mathrm{CI} 1.51-1.93$ ) than those without AC (Figure 2). Intriguingly, patients who received NAC also had significantly worse bladder cancerspecific survival (adjusted hazard ratio 1.29, 95\%CI 1.05-1.57) and recurrence-free survival (adjusted hazard ratio 1.66, 95\%CI 1.45-1.89) (Figures 2B-C). 
Next, we evaluated whether we could identify specific subgroups who had a worse or better clinical outcome when receiving NAC (Table 3). Overall survival was significantly worse in patients who received NAC in the years 2000-2012 compared to those not receiving NAC in the same period (adjusted hazard ratio 1.41, 95\%CI 1.13-1.76). In 2013-2016, patients who had received NAC had significantly better overall survival rates in univariable analyses (odds ratio $0.73,95 \%$ CI $0.55-0.97$ ), but this difference was not significant when adjusting for differences in baseline characteristics (adjusted odds ratio 0.78, 95\%CI 0.58-1.06). Similar results were observed for bladder cancer-specific survival, in which the adjusted hazard ratio for NAC use was 1.59 (95\%CI 1.24-2.03) for those treated in 2000-2012, and 0.87 (95\%CI 0.62-1.21) for those treated in 2013-2016. Indeed, when comparing Kaplan-Meier curves of patients treated in 2013-2016, there was significant separation of the overall survival curves (Figure 3A), while the bladder cancer-specific and recurrence-free survival curves were mostly overlapping (Figures 3B-3C). Patients treated with NAC in 2013-2016 had significantly better overall survival compared to those without NAC (Supplementary Figure 1). Furthermore, comparing patients treated with NAC in 2000-2012 to those treated with NAC in 2013-2016, survival had significantly improved in recent years (Supplementary Figure 2). For all other subgroups evaluated (Table 3), patients in all subgroups tended to have a worse bladder cancer-specific survival when receiving NAC compared to those without NAC. Bladder cancer-specific survival was significantly worse for patients receiving NAC and aged $<70$ years (adjusted hazard ratio $1.38,95 \%$ CI 1.09-1.75), men (adjusted hazard ratio 1.28, 95\%CI 1.02-1.61), patients with a Charlson's comorbidity index below (adjusted hazard ratio 1.29, 95\%CI 1.01-1.66), or at/above 7 (adjusted hazard ratio $1.47,95 \% \mathrm{CI} 1.05-2.06$ ), or surgery in an university-affiliated hospital (adjusted hazard ratio $1.50,95 \% \mathrm{CI} 1.16-1.93$ ).

Considering the relative difference in clinical outcome in patients treated with NAC and surgery in 2000-2012 and those treated in 2013-2016, we evaluated which variables independently predicted NAC use in the more recent cohort (Table 4). Baseline and surgery characteristics of this cohort are reported in Supplementary Table 3. In a multivariable analysis, NAC use was higher in patients who were treated more recently (adjusted odds ratio 1.34, 95\% CI 1.14-1.58, per 1-year increment), younger patients (adjusted odds ratio $0.71,95 \% \mathrm{CI}$ 0.64-0.80, per 5-year increment), patients living closer to the hospital of surgery (adjusted odds ratio $0.88,95 \% \mathrm{CI} 0.77-0.99$, per $50 \mathrm{~km}$ increment), and patients treated in university-affiliated hospitals (adjusted odds ratio 1.86, 95\%CI 1.06-3.29). Of all patients undergoing radical cystectomy in university-affiliated hospitals in 2013-2016, 18.7\% (126/673) received NAC, compared to $14.7 \%(75 / 509)$ in non-academic hospitals. In 2015-2016, these percentages had increased to $23.0 \%(75 / 326)$ and $16.3 \%(38 / 233)$, respectively, indicating a continuing trend towards increased NAC use in both hospital types.

\section{Discussion}


This is the first study that evaluated the use of POC in bladder cancer patients undergoing radical cystectomy in Quebec. POC use, particularly NAC, has increased since 2000. As AC is only recommended for patients who did not receive NAC, the increase in NAC use resulted in a decrease in AC use, 2012 being the first year that NAC surpassed AC use. In 2015, POC use was $28.6 \%$, with $20.7 \%$ of the patients receiving NAC and $7.9 \%$ of patients receiving AC. Although POC use is increasing, aforementioned percentages are lower than generally reported in other countries. ${ }^{11,12}$

Similar to other recent studies, chemotherapy use was similar in men and women, but we observed a lower use of POC, both for neoadjuvant and AC, in older patients and those with a higher Charlson's comorbidity index. ${ }^{12}$ This likely reflects decreased eligibility for POC in these subgroups. ${ }^{1}$ Interestingly, a longer distance between a patient's residence and the hospital of surgery independently predicted decreased chemotherapy use, both for POC use in the whole cohort and for NAC use in patients treated in 2013-2016. As such, we are the first Canadian study to identify distance to the hospital as a predictor for NAC and POC use. While we do not have staging information available, it is unlikely that patients residing further from the hospital would have less advanced tumors at radical cystectomy. It is more probable that reduced accessibility to care resulted in the observed difference. One study from the United States also observed that increased travel distance was negatively associated with POC use. ${ }^{21}$ This is a concern for sparsely populated countries such as Canada, and may be an important explanation as to why POC use in both Quebec and Ontario ${ }^{14}$ is lower than in most other countries. In a previously published manuscript in which we used the same database as in the current manuscript, we reported that patients residing further from the hospital of surgery had worse overall and bladder cancer-specific survival. ${ }^{15}$ The reduced use of POC in patients living further away from the hospital of surgery might contribute to the worse long-term outcome of these patients. While future studies will need to confirm such a correlation, based on our data, we think it is important for policymakers to ensure appropriate accessibility to POC for patients living in remote areas.

In our cohort, NAC use was significantly higher in university-affiliated hospitals, both in the whole cohort and in the patients treated in 2013-2016. This may indicate slower adaptation to the new guidelines in non-academic hospitals. Alternatively, various authors, including Raphael and Booth, ${ }^{22}$ have suggested that POC use would increase with increased referrals of patients to medical oncologists and multidisciplinary teams. Perhaps the access to medical oncologists and/or the availability of multidisciplinary teams is lower in non-academic hospitals, and/or physicians in non-academic hospitals referred suitable candidates for POC to academic hospitals.

Several considerations need to be made when interpreting our findings. The Quebec administrative databases do not contain information on pathological or clinical staging of tumors, and due to privacy legislation, we are unable to link these data to pathology reports in hospitals. This lack of information is crucial for interpretation of our analyses. For example, patients who 
received AC consistently had a worse clinical outcome. However, since adjuvant therapy is only recommended for patients with more advanced bladder cancer, this difference is likely caused by selection bias. Similarly, although overall survival was improved in patients treated with NAC in 2013-2016, in other survival curves patients who received NAC had similar or even worse clinical outcome than those who did not receive POC. Previous studies have reported that NAC use is relatively higher in patients with more advanced bladder cancer. ${ }^{12}$ Since NAC is increasingly administered in our cohort, it is plausible that more recently, patients with less advanced bladder cancer increasingly received NAC, resulting in the relative improved survival rates for NAC. This hypothesis is supported by the fact that patients treated with NAC in 20132016 had better survival rates than those treated before 2013. Also, misclassification may have occurred. For example, the Charlson's comorbidity index would have been incorrect if medical staff incorrectly filed diagnostic codes, or physicians may have incorrectly filed or forgot to file administration of chemotherapy. We were unable to determine the exact chemotherapy regimen administered to patients. Due to database limitations, we had to assume that patients who recurred, received treatment for their recurrence or died within a short period of time, thereby overestimating the time to recurrence. Similarly, we may have underestimated the time to recurrence if patients initiated adjuvant therapy more than three months after postoperative discharge. Finally, in the subgroup analyses, some groups had low patient numbers, decreasing the power of these analyses.

The strengths of our study include the large cohort size, virtually including all cases of radical cystectomy in Quebec, the relatively long follow-up, and extensive demographic and administrative information.

\section{Conclusions}

The use of POC, and particularly NAC, has increased in bladder cancer patients undergoing radical cystectomy in Quebec between 2000 and 2016, but is still lower than its use in other developed countries. Distance between a patient's residence and the hospital of surgery was inversely associated with POC receipt, including NAC. Other predictors for increased POC use included a lower age, fewer comorbidities, surgery in academic hospitals, and treatment by higher volume surgeons. 


\section{References}

1. Kulkarni GS, Black PC, Sridhar SS, et al. Canadian Urological Association guideline: muscle-invasive bladder cancer. Can Urol Assoc J 2019.

2. Grossman HB, Natale RB, Tangen CM, et al. Neoadjuvant chemotherapy plus cystectomy compared with cystectomy alone for locally advanced bladder cancer. $N$ Engl J Med 2003;349:859-66.

3. Sherif A, Holmberg L, Rintala E, et al. Neoadjuvant cisplatinum based combination chemotherapy in patients with invasive bladder cancer: a combined analysis of two Nordic studies. Eur Urol 2004;45:297-303.

4. Advanced Bladder Cancer (ABC) Meta-analysis Collaboration. Neoadjuvant chemotherapy in invasive bladder cancer: a systematic review and meta-analysis. Lancet 2003;361:1927-34.

5. Sternberg CN, Donat SM, Bellmunt J, et al. Chemotherapy for bladder cancer: treatment guidelines for neoadjuvant chemotherapy, bladder preservation, adjuvant chemotherapy, and metastatic cancer. Urology 2007;69:62-79.

6. Fahmy O, Khairul-Asri MG, Schubert T, et al. A systematic review and meta-analysis on the oncological long-term outcomes after trimodality therapy and radical cystectomy with or without neoadjuvant chemotherapy for muscle-invasive bladder cancer. Urol Oncol 2018;36:43-53.

7. Jerlstrom $\mathrm{T}$, Chen R, Liedberg F, et al. No increased risk of short-term complications after radical cystectomy for muscle-invasive bladder cancer among patients treated with preoperative chemotherapy: a nation-wide register-based study. World J Urol 2019.

8. Kim DK, Lee JY, Jung JH, Hah YS, Cho KS. Role of adjuvant cisplatin-based chemotherapy following radical cystectomy in locally advanced muscle-invasive bladder cancer: Systematic review and meta-analysis of randomized trials. Investigative and clinical urology 2019;60:64-74.

9. Oedorf K, Skaaheim Haug E, Liedberg F, et al. Perioperative management of radical cystectomy in the Nordic countries. Scandinavian journal of urology 2019:1-5.

10. Sherif A. The long perspective in emergence of neoadjuvant chemotherapy for bladder cancer in Ontario, Canada-space for improvement with regular and organized multidisciplinary team meetings. Translational andrology and urology 2018;7:508-10.

11. Anan G, Hatakeyama S, Fujita N, et al. Trends in neoadjuvant chemotherapy use and oncological outcomes for muscle-invasive bladder cancer in Japan: a multicenter study. Oncotarget 2017;8:86130-42.

12. Duplisea JJ, Mason RJ, Reichard CA, et al. Trends and disparities in the use of neoadjuvant chemotherapy for muscle-invasive urothelial carcinoma. Can Urol Assoc $J$ 2019;13:24-8.

13. Kim SH, Seo HK, Shin HC, et al. Trends in the Use of Chemotherapy before and after Radical Cystectomy in Patients with Muscle-invasive Bladder Cancer in Korea. $J$ Korean Med Sci 2015;30:1150-6. 
14. Booth CM, Karim S, Brennan K, Siemens DR, Peng Y, Mackillop WJ. Perioperative chemotherapy for bladder cancer in the general population: Are practice patterns finally changing? Urol Oncol 2018;36:89.e13-89.e20.

15. Wissing MD, Santos F, Zakaria AS, et al. Short- and long-term survival has improved after radical cystectomy for bladder cancer in Quebec during the years 2000-2015. J Surg Oncol 2019.

16. Charlson M, Szatrowski TP, Peterson J, Gold J. Validation of a combined comorbidity index. Journal of clinical epidemiology 1994;47:1245-51.

17. Charlson ME, Pompei P, Ales KL, MacKenzie CR. A new method of classifying prognostic comorbidity in longitudinal studies: development and validation. Journal of chronic diseases 1987;40:373-83.

18. Kaplan EL, Meier P. Nonparametric estimation from incomplete observations. Journal of the American statistical association 1958;53:457-81.

19. Schemper M, Smith TL. A note on quantifying follow-up in studies of failure time. Control Clin Trials 1996;17:343-6.

20. Cox DR. Regression Models and Life-Tables. Journal of the Royal Statistical Society. Series B (Methodological) 1972;34:187-220.

21. Reardon ZD, Patel SG, Zaid HB, et al. Trends in the use of perioperative chemotherapy for localized and locally advanced muscle-invasive bladder cancer: a sign of changing tides. Eur Urol 2015;67:165-70.

22. Raphael MJ, Booth CM. Neoadjuvant chemotherapy for muscle-invasive bladder cancer: Underused across the 49(th) parallel. Can Urol Assoc J 2019;13:29-31. 
Figures and Tables

Fig. 1. Percentage of patients receiving neoadjuvant and adjuvant chemotherapy, by year.

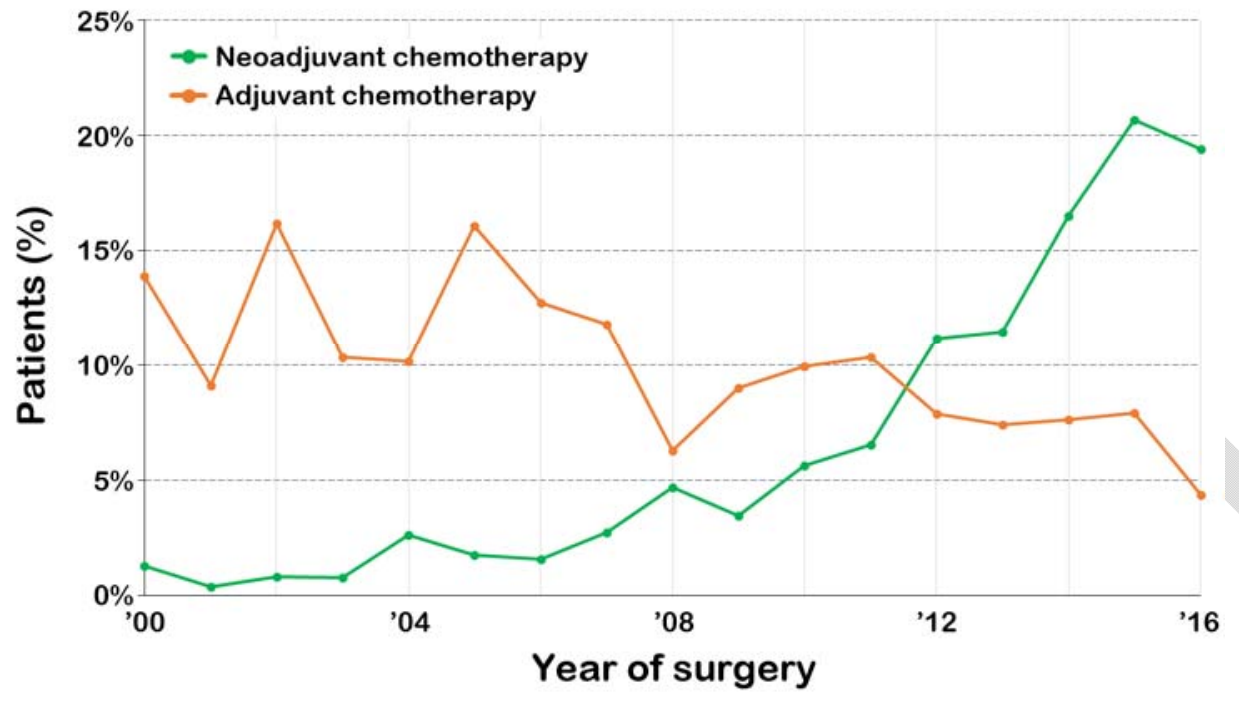


Fig. 2. (A) Overall, (B) bladder cancer-specific, and (C) recurrence-free survival. Patients were stratified by neoadjuvant chemotherapy use. Covariates in the multivariable model included year of surgery, age, sex, Charlson's comorbidity index, region of residence and hospital, distance between residence and hospital, type of hospital, hospital size, and hospital's and surgeons' radical cystectomy volume.
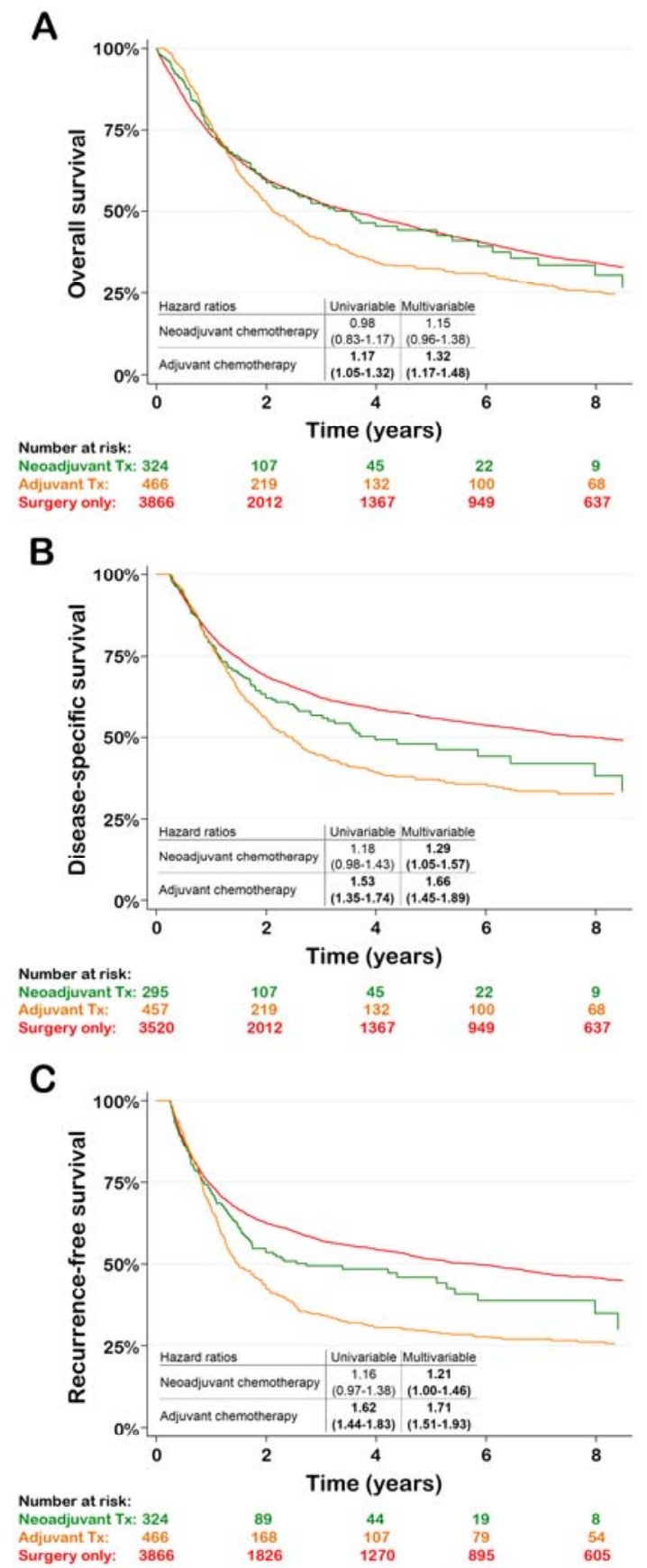
Fig. 3. (A) Overall, (B) bladder cancer-specific, and (C) recurrence-free survival of patients treated from 2013-2016. Patients were stratified by neoadjuvant chemotherapy use. Covariates in the multivariable model included year of surgery, age, sex, Charlson's comorbidity index, region of residence and hospital, distance between residence and hospital, type of hospital, hospital size, and hospital's and surgeons' radical cystectomy volume.
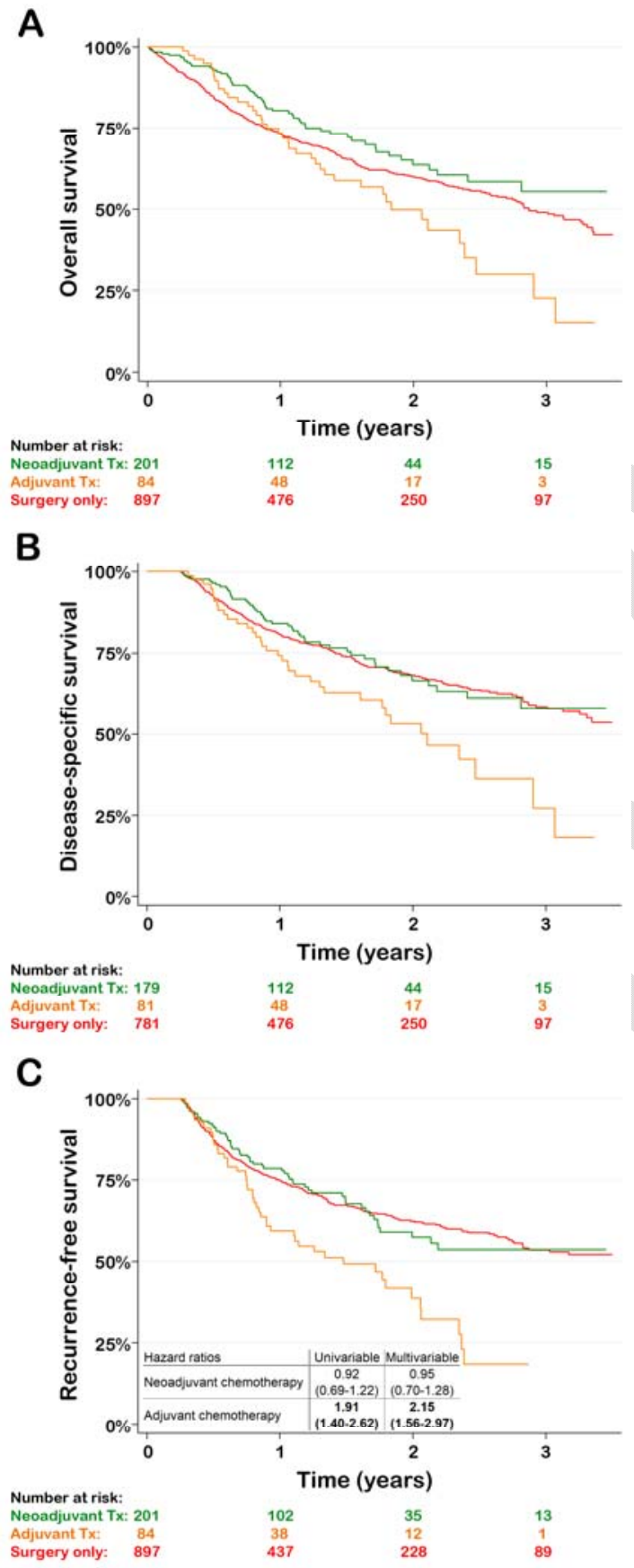


\begin{tabular}{|c|c|c|c|c|}
\hline \multicolumn{5}{|c|}{ Table 1. Baseline characteristics } \\
\hline & $\begin{array}{c}\text { No } \\
\text { perioperative } \\
\text { chemotherapy }\end{array}$ & $\begin{array}{l}\text { Perioperative } \\
\text { chemotherapy }\end{array}$ & $\begin{array}{l}\text { Neoadjuvant } \\
\text { chemotherapy }\end{array}$ & $\begin{array}{c}\text { Adjuvant } \\
\text { chemotherapy }\end{array}$ \\
\hline Number of patients & 3866 & 790 & 324 & 466 \\
\hline Age & $70(63-76)$ & $64(58-70)$ & $64(58-69)$ & $64(58-70)$ \\
\hline \multicolumn{5}{|l|}{ Sex } \\
\hline Male & $2939(76.0 \%)$ & $607(76.8 \%)$ & $243(75.0 \%)$ & $364(78.1 \%)$ \\
\hline Female & $927(24.0 \%)$ & $183(23.2 \%)$ & $81(25.0 \%)$ & $102(21.9 \%)$ \\
\hline $\begin{array}{l}\text { Charlson's comorbidity } \\
\text { index }\end{array}$ & $7(5-8)$ & $5(4-7)$ & $5(4-7)$ & $5(4-7)$ \\
\hline Index $\geq 10$ & $\begin{array}{c}12.9 \% \\
(499 / 3866) \\
\end{array}$ & $\begin{array}{c}3.8 \% \\
(30 / 790) \\
\end{array}$ & $\begin{array}{l}2.2 \% \\
(7 / 324) \\
\end{array}$ & $\begin{array}{c}4.9 \% \\
(23 / 466) \\
\end{array}$ \\
\hline \multicolumn{5}{|l|}{ Region of residence } \\
\hline $\begin{array}{l}\text { Regions with cities with } \\
>400000 \text { inhabitants }\end{array}$ & $1454(37.6 \%)$ & $291(36.8 \%)$ & $110(34.0 \%)$ & $181(38.8 \%)$ \\
\hline $\begin{array}{l}\text { Regions with cities with } \\
100000-400000 \\
\text { inhabitants }\end{array}$ & $2121(54.9 \%)$ & $450(57.0 \%)$ & $194(59.9 \%)$ & $256(54.9 \%)$ \\
\hline $\begin{array}{l}\text { Rural regions (largest } \\
\text { city in region }<100000 \\
\text { inhabitants) }\end{array}$ & $265(6.9 \%)$ & $39(4.9 \%)$ & $14(4.3 \%)$ & $25(5.4 \%)$ \\
\hline Unknown & $26(0.7 \%)$ & $10(1.3 \%)$ & $6(1.9 \%)$ & $4(0.9 \%)$ \\
\hline \multicolumn{5}{|l|}{$\begin{array}{l}\text { Region of hospital of } \\
\text { surgery }\end{array}$} \\
\hline $\begin{array}{l}\text { Regions with cities with } \\
>400000 \text { inhabitants }\end{array}$ & $2301(59.5 \%)$ & $475(60.1 \%)$ & $197(60.8 \%)$ & $278(59.7 \%)$ \\
\hline $\begin{array}{l}\text { Regions with cities with } \\
100000-250000 \\
\text { inhabitants }\end{array}$ & $1524(39.4 \%)$ & $309(39.1 \%)$ & $127(39.2 \%)$ & $182(39.1 \%)$ \\
\hline $\begin{array}{l}\text { Rural regions (largest } \\
\text { city in region }<100000 \\
\text { inhabitants) }\end{array}$ & $41(1.1 \%)$ & $6(0.8 \%)$ & $0(0.0 \%)$ & $6(1.3 \%)$ \\
\hline $\begin{array}{l}\text { Distance (in } \mathrm{km} \text { ) between } \\
\text { residence and hospital }\end{array}$ & $20(8-77)$ & $21(9-57)$ & $24(11-59)$ & $19(8-57)$ \\
\hline \multicolumn{5}{|l|}{ Type of hospital } \\
\hline $\begin{array}{l}\text { University-affiliated } \\
\text { hospital }\end{array}$ & $1960(50.7 \%)$ & $427(54.1 \%)$ & $199(61.4 \%)$ & $228(48.9 \%)$ \\
\hline Other hospital & $1906(49.3 \%)$ & $363(45.9 \%)$ & $125(38.6 \%)$ & $238(51.1 \%)$ \\
\hline \multicolumn{5}{|l|}{ Hospital size } \\
\hline$<250$ beds & $287(7.4 \%)$ & $53(6.7 \%)$ & $12(3.7 \%)$ & $41(8.8 \%)$ \\
\hline $250-499$ beds & $1888(48.8 \%)$ & $432(54.7 \%)$ & $152(46.9 \%)$ & $280(60.1 \%)$ \\
\hline
\end{tabular}




\begin{tabular}{|c|c|c|c|c|}
\hline$\geq 500$ beds & $1691(43.7 \%)$ & $304(38.5 \%)$ & $159(49.1 \%)$ & $145(31.1 \%)$ \\
\hline Unknown & $0(0.0 \%)$ & $1(0.1 \%)$ & $1(0.3 \%)$ & $0(0.0 \%)$ \\
\hline \multicolumn{5}{|l|}{$\begin{array}{l}\text { Radical cystectomy } \\
\text { volume/active year }\end{array}$} \\
\hline Hospital & $\begin{array}{c}13.4 \\
(7.8-32.2)\end{array}$ & $\begin{array}{c}13.8 \\
(7.8-32.2)\end{array}$ & $\begin{array}{c}16.1 \\
(9.9-32.2)\end{array}$ & $\begin{array}{c}12.8 \\
(5.8-32.2)\end{array}$ \\
\hline Surgeon & $7.3(4.7-13.1)$ & $8.6(4.9-13.4)$ & $\begin{array}{c}10.3 \\
(5.7-13.4)\end{array}$ & $8.1(4.7-13.4)$ \\
\hline $\begin{array}{l}\text { Time (days) from last } \\
\text { cystoscopy/TURB to } \\
\text { surgery }\end{array}$ & $49(28-76)$ & $56(32-118)$ & $126(56-167)$ & $42(27-62)$ \\
\hline
\end{tabular}

Continuous variables are displayed as the median (interquartile range). Categorical variables are displayed as patient number (percentage). TURB: transurethral resection of the bladder.

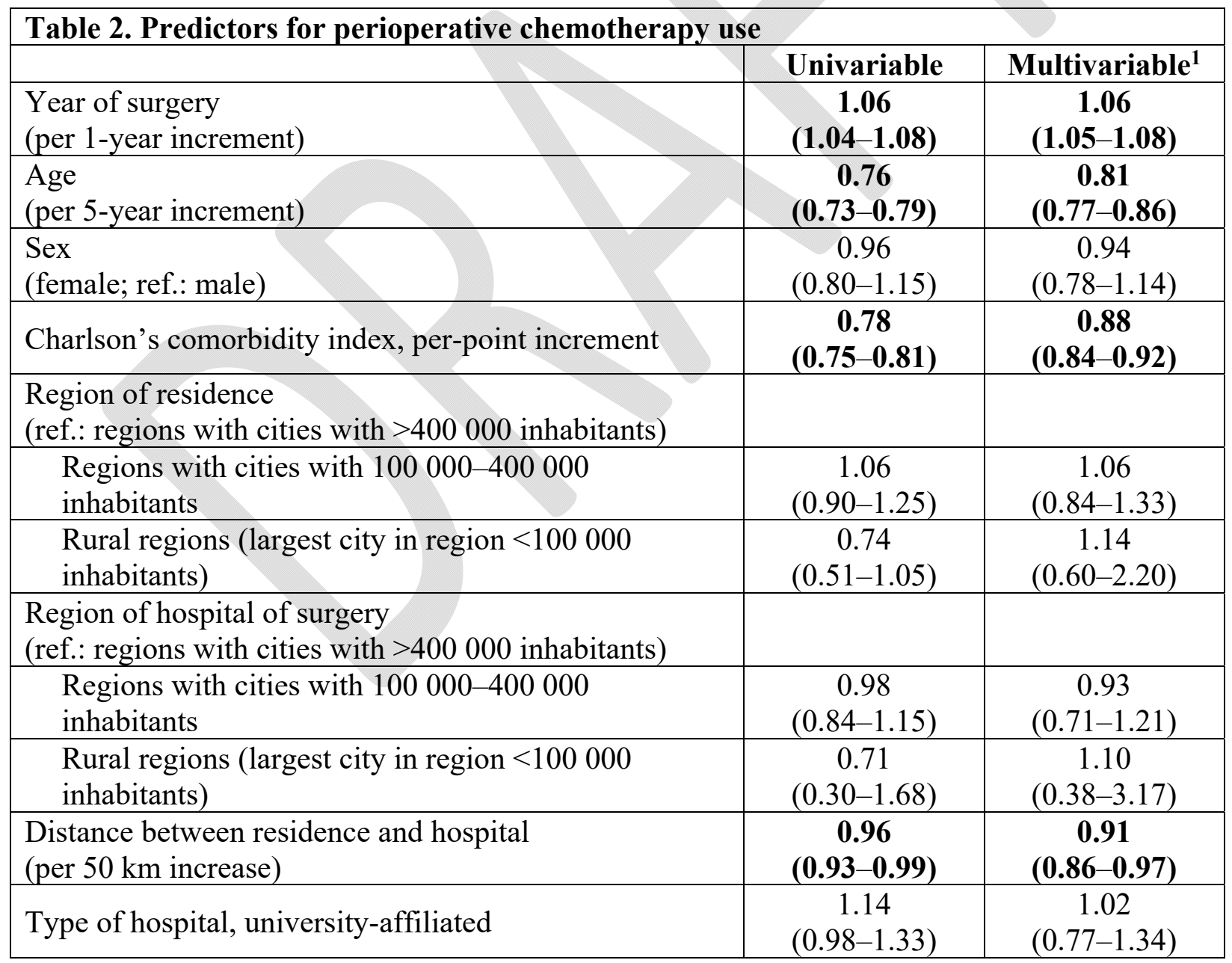




\begin{tabular}{|l|c|c|}
\hline $\begin{array}{l}\text { Hospital size } \\
\text { (ref.: } \geq 500 \text { beds) }\end{array}$ & \\
\hline $250-499$ beds & $\begin{array}{c}\mathbf{1 . 2 7} \\
\mathbf{( 1 . 0 8}-\mathbf{1 . 4 9 )}\end{array}$ & $\begin{array}{c}\mathbf{1 . 4 5} \\
\mathbf{( 1 . 2 0}-\mathbf{1 . 7 6 )}\end{array}$ \\
\hline$<250$ beds & 1.03 & 1.01 \\
$(0.75-1.41)$ & $(0.70-1.45)$ \\
\hline $\begin{array}{l}\text { Hospital's radical cystectomy volume } \\
\text { (per 5/active year increment) }\end{array}$ & 1.02 & $\mathbf{0 . 9 1}$ \\
\hline $\begin{array}{l}\text { Surgeon's radical cystectomy volume } \\
\text { (per 5/active year increment) }\end{array}$ & $(1.00-1.05)$ & $\mathbf{( 0 . 8 7 - 0 . 9 6 )}$ \\
\hline
\end{tabular}

Values represent odds ratios with $95 \%$ confidence intervals. ${ }^{1}$ All variables were mutually adjusted for each other.

\begin{tabular}{|c|c|c|c|c|}
\hline & & $\mathbf{S}$ & & SS \\
\hline & Univariable & Multivariable & Univariable & Multivariable \\
\hline Age $\geq 70$ years & $\begin{array}{c}0.98 \\
(0.71-1.35)\end{array}$ & $\begin{array}{c}1.08 \\
(0.78-1.50)\end{array}$ & $\begin{array}{c}1.09 \\
(0.75-1.58)\end{array}$ & $\begin{array}{c}1.16 \\
(0.80-1.70)\end{array}$ \\
\hline Age $<70$ years & $\begin{array}{c}1.18 \\
(0.96-1.45)\end{array}$ & $\begin{array}{c}1.19 \\
(0.96-1.48)\end{array}$ & $\begin{array}{c}1.39 \\
(1.11-1.74)\end{array}$ & $\begin{array}{c}1.38 \\
(1.09-1.75)\end{array}$ \\
\hline Men & $\begin{array}{c}0.95 \\
(0.78-1.16)\end{array}$ & $\begin{array}{c}1.14 \\
(0.93-1.41)\end{array}$ & $\begin{array}{c}1.16 \\
(0.93-1.45)\end{array}$ & $\begin{array}{c}1.28 \\
(1.02-1.61)\end{array}$ \\
\hline Women & $\begin{array}{c}1.07 \\
(0.77-1.50)\end{array}$ & $\begin{array}{c}1.18 \\
(0.83-1.68)\end{array}$ & $\begin{array}{c}1.24 \\
(0.85-1.79)\end{array}$ & $\begin{array}{c}1.32 \\
(0.89-1.97)\end{array}$ \\
\hline $\mathrm{CCI} \geq 7$ & $\begin{array}{c}1.12 \\
(0.83-1.51)\end{array}$ & $\begin{array}{c}1.21 \\
(0.89-1.64)\end{array}$ & $\begin{array}{c}1.41 \\
(1.02-1.96)\end{array}$ & $\begin{array}{c}1.47 \\
(1.05-2.06)\end{array}$ \\
\hline $\mathrm{CCI}<7$ & $\begin{array}{c}0.92 \\
(0.75-1.14)\end{array}$ & $\begin{array}{c}1.18 \\
(0.95-1.48)\end{array}$ & $\begin{array}{c}1.06 \\
(0.84-1.34)\end{array}$ & $\begin{array}{c}1.29 \\
(1.01-1.66)\end{array}$ \\
\hline Year of surgery $2013-2016$ & $\begin{array}{c}0.73 \\
(0.55-0.97)\end{array}$ & $\begin{array}{c}0.78 \\
(0.58-1.06)\end{array}$ & $\begin{array}{c}0.87 \\
(0.64-1.19)\end{array}$ & $\begin{array}{c}0.87 \\
(0.62-1.21)\end{array}$ \\
\hline Year of surgery $2000-2012$ & $\begin{array}{c}1.20 \\
(0.96-1.49)\end{array}$ & $\begin{array}{c}1.41 \\
(1.13-1.76)\end{array}$ & $\begin{array}{c}1.44 \\
(1.13-1.83)\end{array}$ & $\begin{array}{c}1.59 \\
(1.24-2.03)\end{array}$ \\
\hline $\begin{array}{l}\text { Surgery in hospital not } \\
\text { affiliated with a university }\end{array}$ & $\begin{array}{c}0.84 \\
(0.64-1.11)\end{array}$ & $\begin{array}{c}1.00 \\
(0.76-1.33)\end{array}$ & $\begin{array}{c}1.00 \\
(0.74-1.36)\end{array}$ & $\begin{array}{c}1.10 \\
(0.80-1.51)\end{array}$ \\
\hline $\begin{array}{l}\text { Surgery in hospital affiliated } \\
\text { with a university }\end{array}$ & $\begin{array}{c}1.11 \\
(0.89-1.38)\end{array}$ & $\begin{array}{c}1.31 \\
(1.04-1.65)\end{array}$ & $\begin{array}{c}1.33 \\
(1.04-1.69)\end{array}$ & $\begin{array}{c}1.50 \\
(1.16-1.93)\end{array}$ \\
\hline
\end{tabular}

In multivariable analyses, we adjusted for year of surgery, age, sex, Charlson's comorbidity index, region of residence and hospital, distance between residence and hospital, type of hospital, hospital size, and hospital's and surgeons' radical cystectomy volume. CCI: Charlson's comorbidity index; DSS: bladder cancer-specific survival; OS: overall survival. 


\begin{tabular}{|c|c|c|}
\hline & Univariable & Multivariable $^{1}$ \\
\hline $\begin{array}{l}\text { Year of surgery } \\
\text { (per 1-year increment) }\end{array}$ & $\begin{array}{c}1.24 \\
(1.07-1.44)\end{array}$ & $\begin{array}{c}1.34 \\
(1.14-1.58)\end{array}$ \\
\hline $\begin{array}{l}\text { Age } \\
\text { (per 5-year increment) }\end{array}$ & $\begin{array}{c}0.71 \\
(0.66-0.77)\end{array}$ & $\begin{array}{c}0.71 \\
(0.64-0.80)\end{array}$ \\
\hline $\begin{array}{l}\text { Sex } \\
\text { (female; ref.: male) }\end{array}$ & $\begin{array}{c}1.04 \\
(0.72-1.49)\end{array}$ & $\begin{array}{c}1.06 \\
(0.72-1.55)\end{array}$ \\
\hline Charlson's comorbidity index, per-point increment & $\begin{array}{c}0.78 \\
(0.72-0.85)\end{array}$ & $\begin{array}{c}0.98 \\
(0.89-1.09)\end{array}$ \\
\hline \multicolumn{3}{|l|}{$\begin{array}{l}\text { Region of residence } \\
\text { (ref.: regions with cities with }>400000 \text { inhabitants) }\end{array}$} \\
\hline Regions with cities with $100000-400000$ inhabitants & $\begin{array}{c}0.97 \\
(0.69-1.34) \\
\end{array}$ & $\begin{array}{c}0.87 \\
(0.55-1.38) \\
\end{array}$ \\
\hline Rural regions (largest city in region $<100000$ inhabitants) & $\begin{array}{c}0.43 \\
(0.19-0.97)\end{array}$ & $\begin{array}{c}1.35 \\
(0.35-5.22)\end{array}$ \\
\hline \multicolumn{3}{|l|}{$\begin{array}{l}\text { Region of hospital of surgery } \\
\text { (ref.: regions with cities with }>400000 \text { inhabitants) }\end{array}$} \\
\hline Regions with cities with $100000-400000$ inhabitants & $\begin{array}{c}0.98 \\
(0.72-1.33)\end{array}$ & $\begin{array}{c}1.23 \\
(0.73-2.07)\end{array}$ \\
\hline $\begin{array}{l}\text { Distance between residence and hospital } \\
\text { (per } 50 \mathrm{~km} \text { increase) }\end{array}$ & $\begin{array}{c}0.91 \\
(0.84-0.97)\end{array}$ & $\begin{array}{c}0.88 \\
(0.77-0.99)\end{array}$ \\
\hline Type of hospital, university-affiliated & $\begin{array}{c}1.33 \\
(0.98-1.82)\end{array}$ & $\begin{array}{c}1.86 \\
(1.06-3.29)\end{array}$ \\
\hline \multicolumn{3}{|l|}{$\begin{array}{l}\text { Hospital size } \\
\text { (ref.: } \geq 500 \text { beds) }\end{array}$} \\
\hline $250-499$ beds & $\begin{array}{c}0.64 \\
(0.47-0.88)\end{array}$ & $\begin{array}{c}0.93 \\
(0.61-1.42)\end{array}$ \\
\hline$<250$ beds & $\begin{array}{c}0.52 \\
(0.25-1.08)\end{array}$ & $\begin{array}{c}0.62 \\
(0.27-1.45)\end{array}$ \\
\hline $\begin{array}{l}\text { Hospital's radical cystectomy volume } \\
\text { (per 5/active year increment) }\end{array}$ & $\begin{array}{c}0.97 \\
(0.92-1.02) \\
\end{array}$ & $\begin{array}{c}0.91 \\
(0.81-1.01)\end{array}$ \\
\hline $\begin{array}{l}\text { Surgeon's radical cystectomy volume } \\
\text { (per 5/active year increment) }\end{array}$ & $\begin{array}{c}0.98 \\
(0.86-1.12)\end{array}$ & $\begin{array}{c}1.12 \\
(0.85-1.46)\end{array}$ \\
\hline
\end{tabular}

${ }^{1}$ All variables were mutually adjusted for each other. Values represent odds ratios with $95 \%$ confidence intervals. RC: radical cystectomy. 
Supplementary Fig. 1. (A) Overall, (B) bladder cancer-specific, and (C) recurrence-free survival of patients treated from 2013-2016. Patients were stratified by neoadjuvant chemotherapy use. P-values were calculated using log-rank tests.

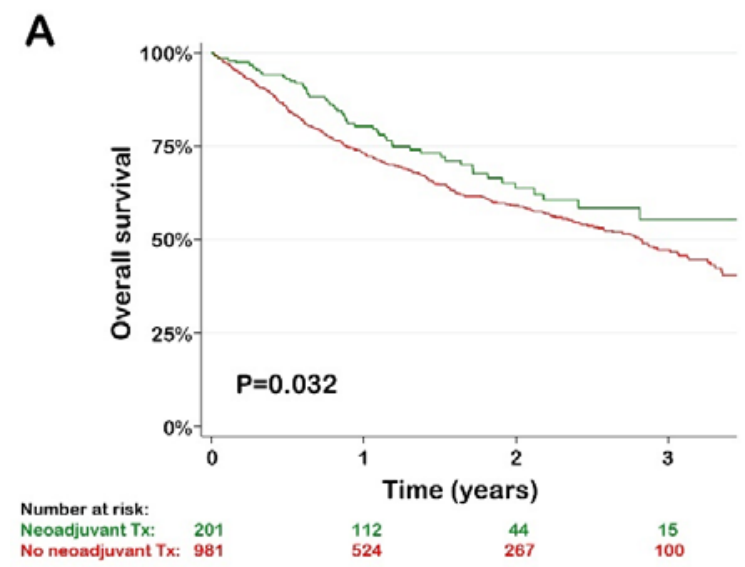

B
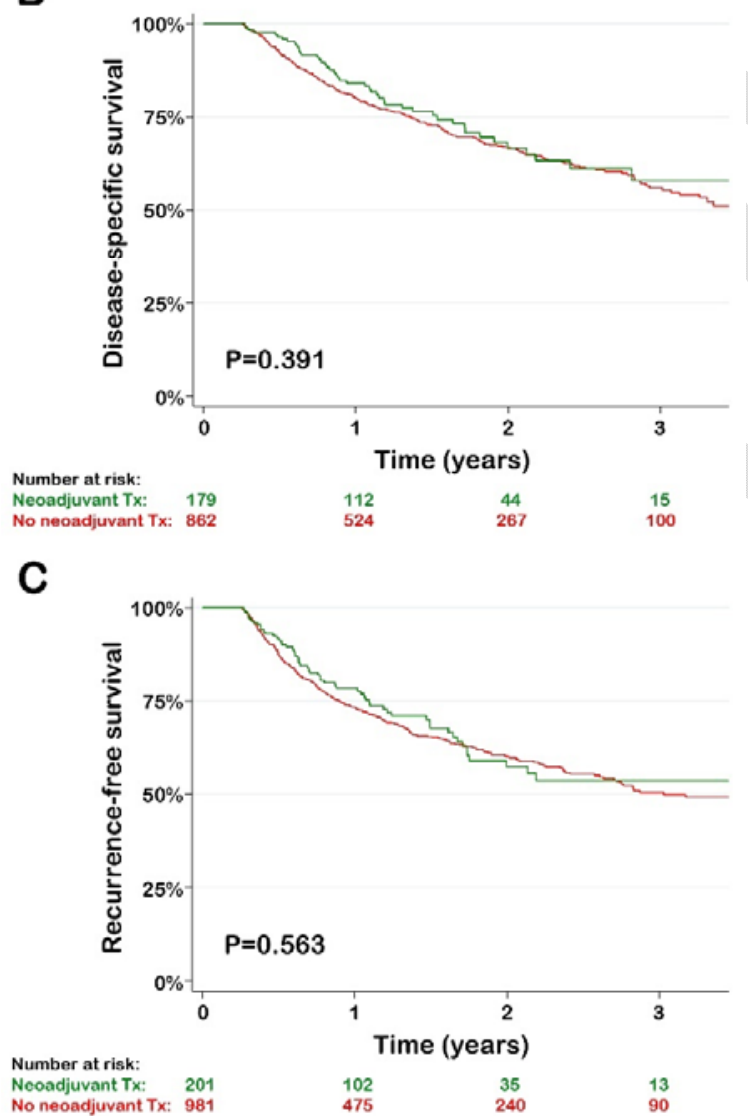
Supplementary Fig. 2. Comparison of (A) overall, (B) bladder cancer-specific, and (C) recurrence-free survival in patients treated with neoadjuvant chemotherapy from 2000-2012 to those treated from 2013-2016. P values were calculated using log-rank tests.
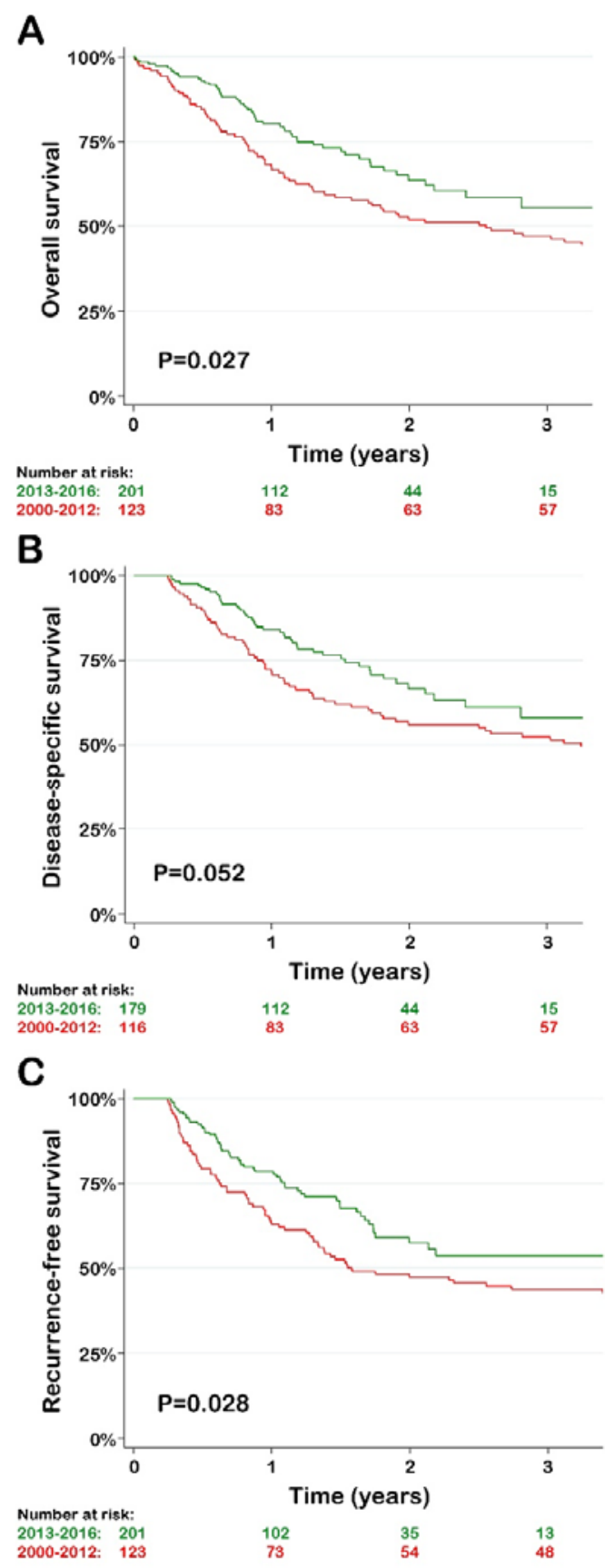


\begin{tabular}{|c|c|c|}
\hline \multicolumn{3}{|c|}{ Supplementary Table 1. Predictors for neoadjuvant chemotherapy use } \\
\hline & Univariable & Multivariable $^{1}$ \\
\hline $\begin{array}{l}\text { Year of surgery } \\
\text { (per 1-year increment) }\end{array}$ & $\begin{array}{c}1.28 \\
(1.24-1.33)\end{array}$ & $\begin{array}{c}1.30 \\
(1.26-1.35)\end{array}$ \\
\hline $\begin{array}{l}\text { Age } \\
\text { (per 5-year increment) }\end{array}$ & $\begin{array}{c}0.78 \\
(0.74-0.83)\end{array}$ & $\begin{array}{c}0.76 \\
(0.71-0.82)\end{array}$ \\
\hline $\begin{array}{l}\text { Sex } \\
\text { (female; ref.: male) }\end{array}$ & $\begin{array}{c}1.07 \\
(0.82-1.39)\end{array}$ & $\begin{array}{c}1.13 \\
(0.85-1.50)\end{array}$ \\
\hline $\begin{array}{l}\text { Charlson's comorbidity index, per point } \\
\text { increment }\end{array}$ & $\begin{array}{c}0.78 \\
(0.73-0.82)\end{array}$ & $\begin{array}{c}0.95 \\
(0.88-1.02)\end{array}$ \\
\hline \multicolumn{3}{|l|}{$\begin{array}{l}\text { Region of residence } \\
\text { (ref:.regions with cities with }>400000 \\
\text { inhabitants) }\end{array}$} \\
\hline $\begin{array}{l}\text { Regions with cities with } 100000-400 \\
000 \text { inhabitants }\end{array}$ & $\begin{array}{c}1.21 \\
(0.95-1.55)\end{array}$ & $\begin{array}{c}0.99 \\
(0.71-1.38)\end{array}$ \\
\hline $\begin{array}{l}\text { Rural regions (largest city in region }<100 \\
000 \text { inhabitants) }\end{array}$ & $\begin{array}{c}0.72 \\
(0.41-1.27)\end{array}$ & $\begin{array}{c}0.92 \\
(0.34-2.50)\end{array}$ \\
\hline \multicolumn{3}{|l|}{$\begin{array}{l}\text { Region of hospital } \\
\text { (ref.: regions with cities with }>400000 \\
\text { inhabitants) }\end{array}$} \\
\hline $\begin{array}{l}\text { Regions with cities with } 100000-400 \\
000 \text { inhabitants }\end{array}$ & $\begin{array}{c}0.97 \\
(0.77-1.23)\end{array}$ & $\begin{array}{c}1.06 \\
(0.72-1.57)\end{array}$ \\
\hline $\begin{array}{l}\text { Distance between residence and hospital } \\
\text { (per } 50 \mathrm{~km} \text { increase) }\end{array}$ & $\begin{array}{c}0.99 \\
(0.95-1.03) \\
\end{array}$ & $\begin{array}{c}0.95 \\
(0.87-1.03) \\
\end{array}$ \\
\hline Type of hospital, university-affiliated & $\begin{array}{c}1.56 \\
(1.24-1.97)\end{array}$ & $\begin{array}{c}1.69 \\
(1.12-2.55)\end{array}$ \\
\hline \multicolumn{3}{|l|}{$\begin{array}{l}\text { Hospital size } \\
\text { (ref.: } \geq 500 \text { beds) }\end{array}$} \\
\hline $250-499$ beds & $\begin{array}{c}0.81 \\
(0.64-1.02)\end{array}$ & $\begin{array}{c}1.19 \\
(0.89-1.59)\end{array}$ \\
\hline$<250$ beds & $\begin{array}{c}0.42 \\
(0.23-0.77)\end{array}$ & $\begin{array}{c}0.54 \\
(0.28-1.08)\end{array}$ \\
\hline $\begin{array}{l}\text { Hospital's radical cystectomy volume } \\
\text { (per 5/active year increment) }\end{array}$ & $\begin{array}{c}1.03 \\
(0.99-1.07)\end{array}$ & $\begin{array}{c}0.89 \\
(0.82-0.96)\end{array}$ \\
\hline $\begin{array}{l}\text { Surgeon's radical cystectomy volume } \\
\text { (per 5/active year increment) }\end{array}$ & $\begin{array}{c}1.15 \\
(1.05-1.26)\end{array}$ & $\begin{array}{c}1.16 \\
(0.95-1.42)\end{array}$ \\
\hline
\end{tabular}

Values represent odds ratios with $95 \%$ confidence intervals. ${ }^{1}$ All variables were mutually adjusted for each other. 


\begin{tabular}{|c|c|c|}
\hline \multicolumn{3}{|c|}{ Supplementary Table 2. Predictors for adjuvant chemotherapy use } \\
\hline & Univariable & Multivariable $^{1}$ \\
\hline $\begin{array}{l}\text { Year of surgery } \\
\text { (per 1-year increment) }\end{array}$ & $\begin{array}{c}0.95 \\
(0.93-0.97)\end{array}$ & $\begin{array}{c}0.95 \\
(0.93-0.97) \\
\end{array}$ \\
\hline $\begin{array}{l}\text { Age } \\
\text { (per 5-year increment) }\end{array}$ & $\begin{array}{c}0.80 \\
(0.76-0.83)\end{array}$ & $\begin{array}{c}0.87 \\
(0.82-0.92) \\
\end{array}$ \\
\hline $\begin{array}{l}\text { Sex } \\
\text { (female; ref.: male) }\end{array}$ & $\begin{array}{c}0.88 \\
(0.70-1.11)\end{array}$ & $\begin{array}{c}0.83 \\
(0.66-1.05)\end{array}$ \\
\hline $\begin{array}{l}\text { Charlson's comorbidity index, per point } \\
\text { increment }\end{array}$ & $\begin{array}{c}0.81 \\
(0.77-0.85)\end{array}$ & $\begin{array}{c}0.86 \\
(0.81-0.91) \\
\end{array}$ \\
\hline \multicolumn{3}{|l|}{$\begin{array}{l}\text { Region of residence } \\
\text { (ref.: regions with cities with }>400000 \\
\text { inhabitants) }\end{array}$} \\
\hline $\begin{array}{l}\text { Regions with cities with } 100000-400 \\
000 \text { inhabitants }\end{array}$ & $\begin{array}{c}0.96 \\
(0.78-1.17) \\
\end{array}$ & $\begin{array}{c}1.09 \\
(0.82-1.45)\end{array}$ \\
\hline $\begin{array}{l}\text { Rural regions (largest city in region }<100 \\
000 \text { inhabitants) }\end{array}$ & $\begin{array}{c}0.77 \\
(0.50-1.20)\end{array}$ & $\begin{array}{c}1.30 \\
(0.58-2.88)\end{array}$ \\
\hline \multicolumn{3}{|l|}{$\begin{array}{l}\text { Region of hospital } \\
\text { (ref.: regions with cities with }>400000 \\
\text { inhabitants) }\end{array}$} \\
\hline $\begin{array}{l}\text { Regions with cities with } 100000-400 \\
000 \text { inhabitants }\end{array}$ & $\begin{array}{c}0.99 \\
(0.81-1.21)\end{array}$ & $\begin{array}{c}0.82 \\
(0.59-1.13)\end{array}$ \\
\hline $\begin{array}{l}\text { Rural regions (largest city in region }<100 \\
000 \text { inhabitants) }\end{array}$ & $\begin{array}{c}1.31 \\
(0.55-3.12) \\
\end{array}$ & $\begin{array}{c}0.98 \\
(0.31-3.07)\end{array}$ \\
\hline $\begin{array}{l}\text { Distance between residence and hospital } \\
\text { (per } 50 \mathrm{~km} \text { increase) }\end{array}$ & $\begin{array}{c}0.95 \\
(0.90-0.99)\end{array}$ & $\begin{array}{c}0.90 \\
(0.83-0.97) \\
\end{array}$ \\
\hline Type of hospital, university-affiliated & $\begin{array}{c}0.90 \\
(0.74-1.09)\end{array}$ & $\begin{array}{c}0.70 \\
(0.50-1.00)\end{array}$ \\
\hline \multicolumn{3}{|l|}{$\begin{array}{l}\text { Hospital size } \\
\text { (ref.: } \geq 500 \text { beds) }\end{array}$} \\
\hline $250-499$ beds & $\begin{array}{c}1.75 \\
(1.42-2.16)\end{array}$ & $\begin{array}{c}1.71 \\
(1.34-2.17)\end{array}$ \\
\hline$<250$ beds & $\begin{array}{c}1.75 \\
(1.21-2.53)\end{array}$ & $\begin{array}{c}1.40 \\
(0.93-2.12)\end{array}$ \\
\hline $\begin{array}{l}\text { Hospital's radical cystectomy volume } \\
\text { (per 5/active year increment) }\end{array}$ & $\begin{array}{c}1.01 \\
(0.98-1.04)\end{array}$ & $\begin{array}{c}0.95 \\
(0.89-1.02)\end{array}$ \\
\hline $\begin{array}{l}\text { Surgeon's radical cystectomy volume } \\
\text { (per 5/active year increment) }\end{array}$ & $\begin{array}{c}1.09 \\
(1.01-1.18)\end{array}$ & $\begin{array}{c}1.34 \\
(1.14-1.59)\end{array}$ \\
\hline
\end{tabular}

Values represent odds ratios with $95 \%$ confidence intervals. ${ }^{1}$ All variables were mutually adjusted for each other. 


\begin{tabular}{|c|c|c|c|c|}
\hline \multicolumn{5}{|c|}{ Supplementary Table 3. Baseline characteristics of patients treated from 2013-2016 } \\
\hline & $\begin{array}{c}\text { No } \\
\text { perioperative } \\
\text { chemotherapy }\end{array}$ & $\begin{array}{l}\text { Perioperative } \\
\text { chemotherapy }\end{array}$ & $\begin{array}{l}\text { Neoadjuvant } \\
\text { chemotherapy }\end{array}$ & $\begin{array}{c}\text { Adjuvant } \\
\text { chemotherapy }\end{array}$ \\
\hline Number of patients & 897 & 285 & 201 & 84 \\
\hline Age & $71(64-76)$ & $65(59-70)$ & $64(58-69)$ & $67(61-72)$ \\
\hline \multicolumn{5}{|l|}{ Sex } \\
\hline Male & $694(77.4 \%)$ & $218(76.5 \%)$ & $154(76.6 \%)$ & $64(76.2 \%)$ \\
\hline Female & $203(22.6 \%)$ & $67(23.5 \%)$ & $47(23.4 \%)$ & $20(23.8 \%)$ \\
\hline $\begin{array}{l}\text { Charlson's comorbidity } \\
\text { index }\end{array}$ & $6(5-8)$ & $5(4-6)$ & $5(4-6)$ & $5(4-7)$ \\
\hline Index $\geq 10$ & $78(8.7 \%)$ & $6(2.1 \%)$ & $4(2.0 \%)$ & $2(2.4 \%)$ \\
\hline \multicolumn{5}{|l|}{ Region of residence } \\
\hline $\begin{array}{l}\text { Regions with cities } \\
\text { with }>400000 \\
\text { inhabitants }\end{array}$ & $277(30.9 \%)$ & $91(31.9 \%)$ & $65(32.3 \%)$ & $26(31.0 \%)$ \\
\hline $\begin{array}{l}\text { Regions with cities } \\
\text { with } 100000-400000 \\
\text { inhabitants }\end{array}$ & $537(59.9 \%)$ & $180(63.2 \%)$ & $123(61.2 \%)$ & $57(67.9 \%)$ \\
\hline $\begin{array}{l}\text { Rural regions (largest } \\
\text { city in region }<100 \\
000 \text { inhabitants) }\end{array}$ & $75(8.4 \%)$ & $8(2.8 \%)$ & $7(3.5 \%)$ & $1(1.2 \%)$ \\
\hline Unknown & $8(0.9 \%)$ & $6(2.1 \%)$ & $6(3.0 \%)$ & $0(0.0 \%)$ \\
\hline \multicolumn{5}{|l|}{$\begin{array}{l}\text { Region of hospital of } \\
\text { surgery }\end{array}$} \\
\hline $\begin{array}{l}\text { Regions with cities } \\
\text { with }>400000 \\
\text { inhabitants }\end{array}$ & $530(59.1 \%)$ & $159(55.8 \%)$ & $118(58.7 \%)$ & $41(48.8 \%)$ \\
\hline $\begin{array}{l}\text { Regions with cities } \\
\text { with } 100000-250000 \\
\text { inhabitants }\end{array}$ & $367(40.9 \%)$ & $126(44.2 \%)$ & $83(41.3 \%)$ & $43(51.2 \%)$ \\
\hline $\begin{array}{l}\text { Rural regions (largest } \\
\text { city in region }<100 \\
000 \text { inhabitants) }\end{array}$ & $0(0.0 \%)$ & $0(0.0 \%)$ & $0(0.0 \%)$ & $0(0.0 \%)$ \\
\hline $\begin{array}{l}\text { Distance (in km) between } \\
\text { residence and hospital }\end{array}$ & $28(10-111)$ & $22(9-56)$ & $23(10-56)$ & $18(7-58)$ \\
\hline \multicolumn{5}{|l|}{ Type of hospital } \\
\hline $\begin{array}{l}\text { University-affiliated } \\
\text { hospital }\end{array}$ & $511(57.0 \%)$ & $162(56.8 \%)$ & $126(62.7 \%)$ & $36(42.9 \%)$ \\
\hline Other hospital & $386(43.0 \%)$ & $123(43.2 \%)$ & $75(37.3 \%)$ & $48(57.1 \%)$ \\
\hline
\end{tabular}




\begin{tabular}{|c|c|c|c|c|}
\hline Hospital size & & & & \\
\hline$<250$ beds & $51(5.7 \%)$ & $25(8.8 \%)$ & $9(4.5 \%)$ & $16(19.0 \%)$ \\
\hline $250-499$ beds & $432(48.2 \%)$ & $114(40.0 \%)$ & $77(38.3 \%)$ & $37(44.0 \%)$ \\
\hline$\geq 500$ beds & $414(46.2 \%)$ & $145(50.9 \%)$ & $114(56.7 \%)$ & $31(36.9 \%)$ \\
\hline Unknown & $0(0.0 \%)$ & $1(0.4 \%)$ & $1(0.5 \%)$ & $0(0.0 \%)$ \\
\hline $\begin{array}{l}\text { Radical cystectomy } \\
\text { volume/active year }\end{array}$ & & & & \\
\hline Hospital & $\begin{array}{c}16.1 \\
(9.9-32.2)\end{array}$ & $\begin{array}{c}16.1 \\
(10.9-32.2)\end{array}$ & $\begin{array}{c}16.1 \\
(12.8-32.2)\end{array}$ & $\begin{array}{c}13.4 \\
(9.9-23.9)\end{array}$ \\
\hline Surgeon & $8.9(5.7-13.4)$ & $9.3(5.7-13.4)$ & $10.3(5.7-13.4)$ & $8.6(5.0-13.1)$ \\
\hline $\begin{array}{l}\text { Time (days) from } \\
\text { cystoscopy/TURB to } \\
\text { surgery }\end{array}$ & $56(33-85)$ & $106(50-155)$ & $133(95-167)$ & $52(33-83)$ \\
\hline
\end{tabular}

Continuous variables are displayed as the median (interquartile range). Categorical variables are displayed as patient number (percentage). TUR-B: transurethral resection of the bladder. 